\title{
Influência de um aterro sanitário e de efluentes domésticos nas águas superficiais do Rio Tarumã e afluentes - AM
}

Izaias Nascimento dos SANTOS ${ }^{1}$, Adriana Maria Coimbra HORBE², Maria do Socorro Rocha da SILVA Sebastião Átila Fonseca MIRANDA ${ }^{3}$

\section{RESUMO}

O rio Tarumã e seus afluentes, os igarapés Matrinchã e da Bolívia (Manaus-AM) estão impactados por resíduos provenientes de um aterro sanitário e secundariamente por esgotos domésticos. Com o intuito de determinar as consequiências desse impacto foram estudadas as características físicas e químicas e quantificados os metais potencialmente tóxicos nas águas em três períodos pluviométricos. Foi constatado que há alterações consideráveis nas características químicas, especialmente em $\mathrm{NH}_{4}^{+}, \mathrm{Ni}, \mathrm{Pb}, \mathrm{Cu}$ e $\mathrm{Zn}$, quando comparados às águas naturais da região. A condutividade, dureza, alcalinidade, $\mathrm{PO}_{4}^{3-}, \mathrm{NH}_{4}^{+}, \mathrm{K}^{+}, \mathrm{Na}^{+}, \mathrm{Ca}^{2+}, \mathrm{Fe}^{3+} \mathrm{e} \mathrm{Mg}^{+}$que foram os índices que melhor qualificaram as águas estudadas, indicam que sua qualidade tende a ser um pouco melhor no início das chuvas no igarapé da Bolívia, mas não há diferenças marcantes à sua montante. Essas variaçōes mostram que o período de amostragem afeta as características da água, mas não por igual e que apesar da tendência de diluição ser maior no final do período chuvoso, não há significativa melhora na qualidade da água nesse período. Não foram constatadas variações químicas na composição das águas em função da contaminação ser proveniente do aterro ou diretamente dos esgotos.

\section{PALAVRAS-CHAVE}

Águas superficiais, esgotos domésticos, metais tóxicos, Amazônia Central.

\section{Influence of a sanitary dirt-fill and domestic effluents in the surface waters of the Taruma River and its tributaries}

\begin{abstract}
The Tarumã River and its tributary the Matrinchã and Bolivia igarapés (Manaus city-AM), are impacted by sanitary landfill and sewage effluent. With the aims to determine the impact were analyzed the physical and chemical characteristics and heavy metals in the surface waters in three different pluviometric periods. The water is highly chemically modified specially by the $\mathrm{NH}_{4}^{+}, \mathrm{Ni}, \mathrm{Pb}, \mathrm{Cu}$ and $\mathrm{Zn}$ in relation to the natural water patterns. Conductivity, alkalinity, $\mathrm{PO}_{4}^{3-}, \mathrm{NH}_{4}^{+}, \mathrm{K}^{+}, \mathrm{Na}^{+}, \mathrm{Ca}^{2+}, \mathrm{Fe}^{3+} \mathrm{e} \mathrm{Mg}^{+}$that were the main parameters for qualifying the water of the studied waters, indicated that the quality of the water improves downstream to the Bolivia igarape in the beginning of the rainy period but with no great differences upstream. These differences suggest that water samples in part of the basin are affect by the time at which they get collected and although the water is more diluted in the end of the rainy period there is no improvement in its quality. The two contamination input sources from sanitary landfill and sewage effluent, were not differentiated.
\end{abstract}

\section{KEY WORDS}

Surface water, sewage effluent, toxic metals, Central Amazon.

\footnotetext{
${ }^{1}$ Só Poços, Av. Rodrigo Otávio Jordão Ramos, 5211, 69077-000, Manaus, AM,

${ }^{2}$ Departamento de Geociências, Universidade Federal do Amazonas Av. Rodrigo Otávio Jordão Ramos 3000, Manaus, AM. E-mail: ahorbe@ufam.edu.br,

${ }^{3}$ Coordenação de Pesquisa em Clima e Recursos Hídricos, Instituto de Pesquisas da Amazônia, Alameda Cosme Ferreira 1756, Cx Postal 478, 69083-000, Manaus, AM.
} 


\section{INTRODUÇÃO}

No aterro sanitário localizado no $\mathrm{km} 19$ da rodovia AM-010 são despejadas, aproximadamente 56.000 toneladas de lixo por mês ( $1 \mathrm{~kg} / \mathrm{hab} / \mathrm{dia})$ que é recoberto por uma camada de solo de aproximadamente $0,5 \mathrm{~m}$ de espessura. Do total de material depositado, a metade é de matéria orgânica e o restante de papel, papelão, plásticos, metais, pano e estopa, madeira, vidro e pedra (Grossi, 1993). O chorume produzido não é canalizado, aflora em vários locais do aterro, escorre livremente e contamina o rio Tarumã e parte dos seus afluentes, que até pouco tempo formavam um dos mais bonitos balneários da cidade. Além do chorume, há aporte de esgotos sanitários provenientes do bairro de Santa Etelvina e dos moradores que vivem ao longo dos afluentes do Tarumã (Fig. 1).

O rio Tarumã localiza-se na zona norte e oeste de Manaus, e juntamente com os igarapés Bolívia, Passarinho, Mariano e Marianinho constituem parte da bacia do Tarumã-Açú, (Fig. 1). Nessa região concentra-se uma população aproximada de 38 hab/ha que cresce continuamente. $\mathrm{O}$ aterro localiza-se na margem direita de um pequeno afluente do igarapé Bolívia, o Matrinchã. Destes somente as nascentes do igarapé Bolívia, que estão na Reserva Florestal Adolfo Ducke, se mantém a salvo da degradação ambiental. Além da contaminação provocada pelo aterro sanitário e por esgotos, atividades agro-industriais, como extraçōes de óleos vegetais, despolpamento de frutas e desmatamentos, influenciam a qualidade das águas.

As águas a montante do aterro sanitário são de cor preta e se correlacionam a outras drenagens não impactadas na região. Esse tipo de água caracteriza-se pelo pH ácido (4 a 6,3), baixa condutividade ( 7 a $\left.27 \mu \mathrm{S} \mathrm{cm}^{-1}\right)$ e teores de $\mathrm{Cl}, \mathrm{SiO}_{2}$ e álcalis inferiores a $7 \mathrm{mg} \mathrm{L}^{-1}$ (Sioli, 1957; Santos et al., 1984; Santos e Ribeiro, 1988, Campos, 1994, Silva et al., 1999 entre outros). As rochas da área são arenitos arcoseanos, quartzo-arenitos, quartzo-grauvacas e brechas intraformacionais da Formação Alter do Chão depositadas em ambiente flúvio-lacustre no Cretáceo Superior (Cunha et al., 1994). Estáo intensamente lateritizadas, formam perfis imaturos constituídos por caulinita, quartzo, goethita, hematita e, às vezes, gibbsita e estão recobertos por solos do tipo Latossolos e Espodossolos (Leal, 1996).

O relevo é formado por colinas com altitudes em torno de 50 $\mathrm{m}$ com até $150 \mathrm{~m}$ de extensão, topos aplanados, vales em V e drenagem com densidade média. O aterro sanitário foi construído, inicialmente no topo de uma dessas colinas, mas atualmente o lixo é acumulado também nas encostas.

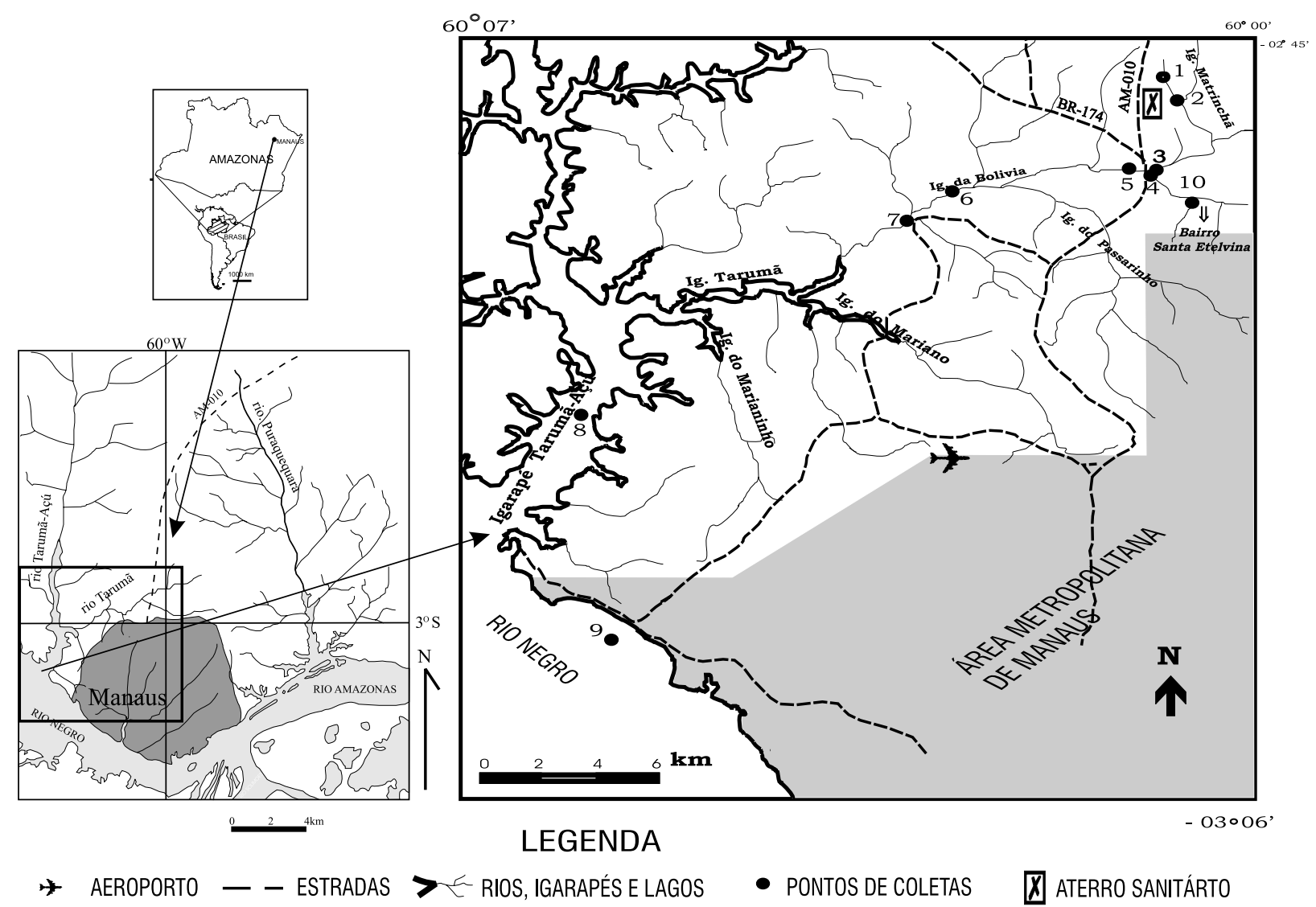

Figura 1- Mapa de localização da área estudada e dos pontos amostrados 
A cobertura vegetal é de floresta tropical em parte preservada na cabeceira do igarapé Bolívia. O restante da área está mais desmatada em conseqüência da maior densidade populacional, especialmente na margem direita do rio Tarumã.

O clima é tropical quente (média de $26^{\circ} \mathrm{C}$ ) e chuvoso (média de $2100 \mathrm{~mm} \mathrm{ano}^{-1}$ ), com o período de maior pluviosidade de dezembro a junho e o de estiagem no restante do ano. Essa variação nos períodos pluviométricos é bastante acentuada de modo que o nível dos principais rios da Amazônia chega a variar em até $16 \mathrm{~m}$, conseqüentemente a diluição provocada pelo aumento da pluviosidade influencia diretamente a composição físico-química das águas.

Com o objetivo de conhecer o impacto e a extensão da contaminaçáo provocada pelo aterro sanitário e pelo aporte de resíduos de esgoto doméstico no rio Tarumã bem como a influência deste nos rios Tarumã-Açú e Negro foram determinados os parâmetros físicos e alguns elementos químicos considerados altamente tóxicos.

\section{MATERIAL E MÉTODOS}

As amostras foram coletadas em janeiro, julho e outubro de 1998, as duas primeiras coincidindo com início e fim do período de maior pluviosidade e a terceira com a época de estiagem. Nesse ano houve uma variação de $12,55 \mathrm{~m}$ no nível das águas entre julho e outubro. As coletas foram realizadas a $20 \mathrm{~cm}$ de profundidade da lâmina de água e armazenadas em garrafas de polietileno, previamente lavadas com solução de $\mathrm{HCl} 10 \%$ e água deionizada. As amostras foram filtradas a vácuo em filtro de membrana de $0,45 \mu \mathrm{m}$ de poro e conservadas com $\mathrm{H}_{2} \mathrm{NO}_{3}$.

Foram coletadas nove amostras ao longo dos igarapés Matrinchã (P1, P2 e P3), Bolivia (P5, P6 e P7) e Tarumã-Açú (P8), além de uma em um igarapé proveniente do bairro de Santa Etelvina (P10) e outra na confluência deste com o Matrinchã (P4). Foram amostradas águas da praia da Ponta Negra, margem esquerda do rio Negro, à jusante da confluência deste com o Tarumã-Açú, a fim de determinar a extensão da contaminação no ponto 9 (Fig. 1). O igarapé Matrinchã (P2) por estar mais próximo do aterro é o que está sobre maior influência deste, enquanto o igarapé representado pelo ponto 10 é afetado diretamente pelos esgotos domésticos provenientes do bairro de Santa Etelvina. Não foram amostradas outras drenagens que deságuam nos igarapés da Bolívia e Tarumã devido a dificuldade de acesso a zona de confluência e esse, também foi o motivo da não amostragem de um ponto no Tarumã-Açú a montante da confluência com o Tarumã.

As medidas de $\mathrm{pH}$ e condutividade elétrica foram feitas no campo por potenciometria; turbidez por turbidimetria; alcalinidade e dureza por titulometria $\mathrm{NO}_{3}^{-}, \mathrm{NO}_{2}^{-}, \mathrm{PO}_{4}^{3-}, \mathrm{Cl}^{-}$ , $\mathrm{NH}_{4}^{+}, \mathrm{Fe}^{2+} \mathrm{e} \mathrm{Fe}^{3+}$ por espectrometria ótica todos analisados em menos de $24 \mathrm{hs}$. As demais análises feitas em 10 dias, foram $\mathrm{Ca}^{2+}$ e $\mathrm{Mg}^{2+}$ por titulometria; $\mathrm{Na}^{+} \mathrm{e} \mathrm{K}^{+}$por fotometria de chama e $\mathrm{Ni}$, $\mathrm{Pb}, \mathrm{Cu}, \mathrm{Zn}, \mathrm{Mn}$ e $\mathrm{Cr}$ por espectrometria de absorção atômica seguindo os critérios do Standard Methods.

Na compilação dos resultados foi aplicado o método utilizado por Haase et al. (1989), que pela análise fatorial obtém o índice de qualidade da água. Para tal foi feito o tratamento estatístico por componentes principais sem rotação no software Statistica 5.0. Isto permite que ao se relacionar as amostras (variáveis) entre si, sejam identificadas as que mais influenciam a composição química das águas considerando-se uma probabilidade de erro entre $0,1 \%$ e $5 \%$. Com base nas variáveis mais significativas foi montada outra matriz de dados e, pela mesma técnica, foram obtidos os escores de cada amostra que correspondem ao índice de qualidade das águas.

\section{RESULTADOS}

\section{PARÂMETROS FÍSICOS E QUÍMICOS}

$\mathrm{O} \mathrm{pH}$ das águas variou entre 3,5 e 6,5, com os valores mais altos no igarapé proveniente de Santa Etelvina (P10) e no Matrinchã (P2) (Fig. 2), o que indica relação com os efluentes domésticos e com o aterro sanitário, respectivamente. Nos demais pontos, os valores são comparáveis aos encontrados em águas naturais na região (Campos, 1994 e Silva et al., 1999). Houve variação segundo a época de coleta (Fig. 2) com águas mais ácidas no final do período chuvoso e mais alcalinas na estiagem o que indica influência direta do volume de água nesse parâmetro.

A condutividade, dureza e alcalinidade variam entre os períodos analisados e têm valores bem mais elevados nos pontos mais afetados pelos esgotos (P10) e pelo aterro sanitário (P2). Contudo, a turbidez também se destaca nos pontos 4 a 7 do
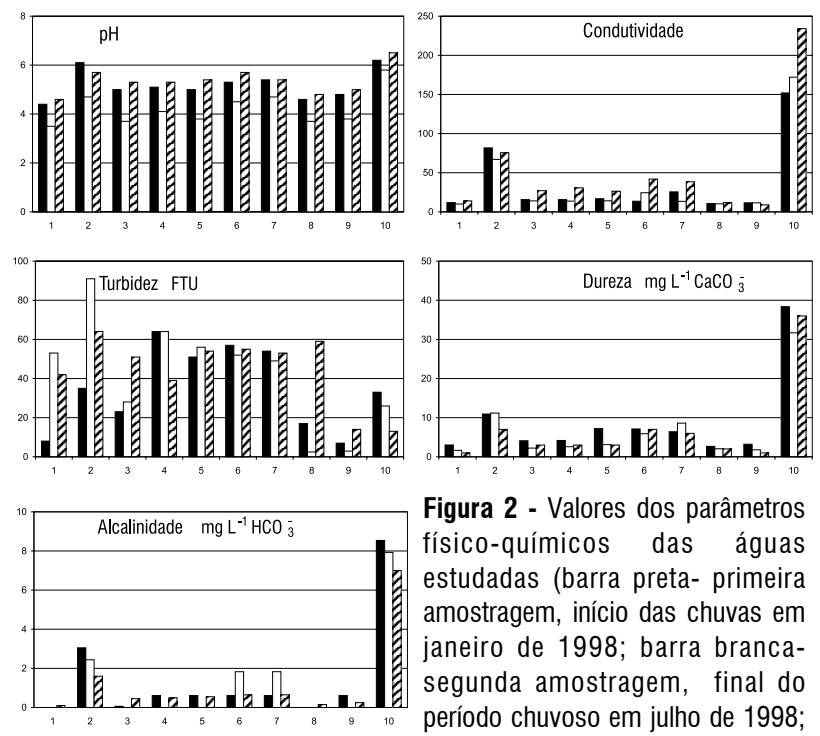

Figura 2 - Valores dos parâmetros físico-químicos das águas estudadas (barra preta- primeira amostragem, início das chuvas em janeiro de 1998; barra brancasegunda amostragem, final do período chuvoso em julho de 1998; barra axurada- terceira amostragem, período de estiagem em outubro de 1998). 
igarapé da Bolívia (P4 e P7) e a condutividade na estiagem nesses mesmos locais (Fig. 2). Dentre esses parâmetros, a turbidez permite diferenciar visualmente as águas mais límpidas no igarapé Matrinchã a montante do aterro (P1 - primeira campanha), no Tarumã-Açú (P8) e no rio Negro (P9) em relação aos demais locais que tem cor esbranquiçada. A água límpida no igarapé Matrinchã na primeira campanha sugeriu que ela poderia servir de "background" da área, contudo, no decorrer dos trabalhos, constatou-se aumento da turbidez devido a ampliação do aterro o que inviabilizou sua utilização como parâmetro comparativo. Comprando-se os dados obtidos com as águas naturais da região (Campos 1994 e Silva et al. 1999) fica evidente o impacto dos efluentes nas características das águas estudadas.

Os valores mais elevados de $\mathrm{pH}$, condutividade, dureza e alcalinidade nos pontos mais afetados pelos esgotos (P10) e pelo aterro sanitário (P2) refletem relação direta com a contaminação. A turbidez elevada em todos os pontos exceto no rio Negro (P9) (Fig. 2) sugere que há aporte de material ao longo do igarapé da Bolívia proveniente de outras fontes além do aterro e o igarapé de Santa Etelvina.

Dentre os elementos analisados $\mathrm{Na}^{+}$e $\mathrm{Cl}^{-}$são os mais abundantes $\left(>0,7 \mathrm{mg} \mathrm{L}^{-1}\right), \mathrm{PO}_{4}^{3-}, \mathrm{NO}_{2}^{-}$e $\mathrm{Fe}^{2+}$ têm as menores concentraçôes $\left(<0,056 \mathrm{mg} \mathrm{L}^{-1}\right)$ e os demais $\left(\mathrm{NO}_{3}^{-}, \mathrm{NH}_{4}^{+}, \mathrm{Ca}^{2+}\right.$, $\mathrm{K}^{+}, \mathrm{Mg}^{2+} \mathrm{e} \mathrm{Fe}^{3+}$ ) têm teores intermediários (Fig 3). Todos são bem mais elevados que o máximo encontrado nas águas naturais na região de Manaus (Campos, 1994 e Silva et al., 1999), exceto $\mathrm{Cl}^{-}$, que excedeu somente no igarapé Matrinchã (P1 e P2) e no proveniente do bairro de Santa Etelvina (P10). As concentrações de $\mathrm{Fe}^{2+}, \mathrm{Fe}^{3+}$ e $\mathrm{PO}_{4}^{3-}$ no Tarumã-Açú e no rio Negro (P8 e P9 respectivamente) são semelhantes às águas naturais.

Entre os pontos, os teores de $\mathrm{Na}^{+}, \mathrm{Cl}^{-}, \mathrm{PO}_{4}^{3-}, \mathrm{NH}_{4}^{+}, \mathrm{Ca}^{2+}$, $\mathrm{K}^{+}, \mathrm{Fe}^{3+}$ são mais altos no Matrinchã (P2) e no igarapé de Santa Etelvina (P10), contudo $\mathrm{NO}_{3}^{-}, \mathrm{NO}_{2}^{-}, \mathrm{Fe}^{2+} \mathrm{e} \mathrm{Mg}^{2+}$ apresentam concentrações bastante variáveis no restante da drenagem e inclusive superam os demais íons nos pontos 6 e 7 do igarapé da Bolívia (Fig. 3).

Entre os períodos alguns elementos variam muito de teores, especialmente no igarapé Matrinchã (P2) e na água proveniente do bairro de Santa Etelvina (P10). Dentre eles destacam-se $\mathrm{PO}_{4}^{3-}$ , $\mathrm{NO}_{3}^{-}, \mathrm{NO}_{2}^{-}, \mathrm{NH}_{4}^{+}, \mathrm{Fe}^{3+}, \mathrm{Fe}^{2+}$ e $\mathrm{Mg}^{2+}$ (Fig. 3) sem, contudo mostrarem um padrão comum.

Considerando-se $\mathrm{NH}_{4}{ }_{4}, \mathrm{NO}_{2} ; \mathrm{NO}_{3} ; \mathrm{Fe}^{2+} \mathrm{e} \mathrm{Fe}^{3+}$ cujos teores estão diretamente relacionados à variação no ambiente entre redutor e oxidante, observa-se que não há correlação de teor entre o par redutor $\left(\mathrm{NH}_{4}^{+}, \mathrm{Fe}^{2+}\right)$ e o oxidante $\left(\mathrm{NO}_{3}^{-}, \mathrm{Fe}^{3+}\right)$, ou seja, enquanto o $\mathrm{NH}_{4}^{+}$é mais elevado dentre os compostos nitrogenados, o $\mathrm{Fe}^{3+}$ é mais elevado que o $\mathrm{Fe}^{2+}$ (Fig. 3) apesar deste último cátion permanecer estável até $\mathrm{pH} 8 \mathrm{em}$ ambiente mais redutor (Hem, 1970). Isto poderia ser conseqüência do aporte de ferro na forma oxidada compatível com a abundância de crostas lateríticas ferruginosas na região.
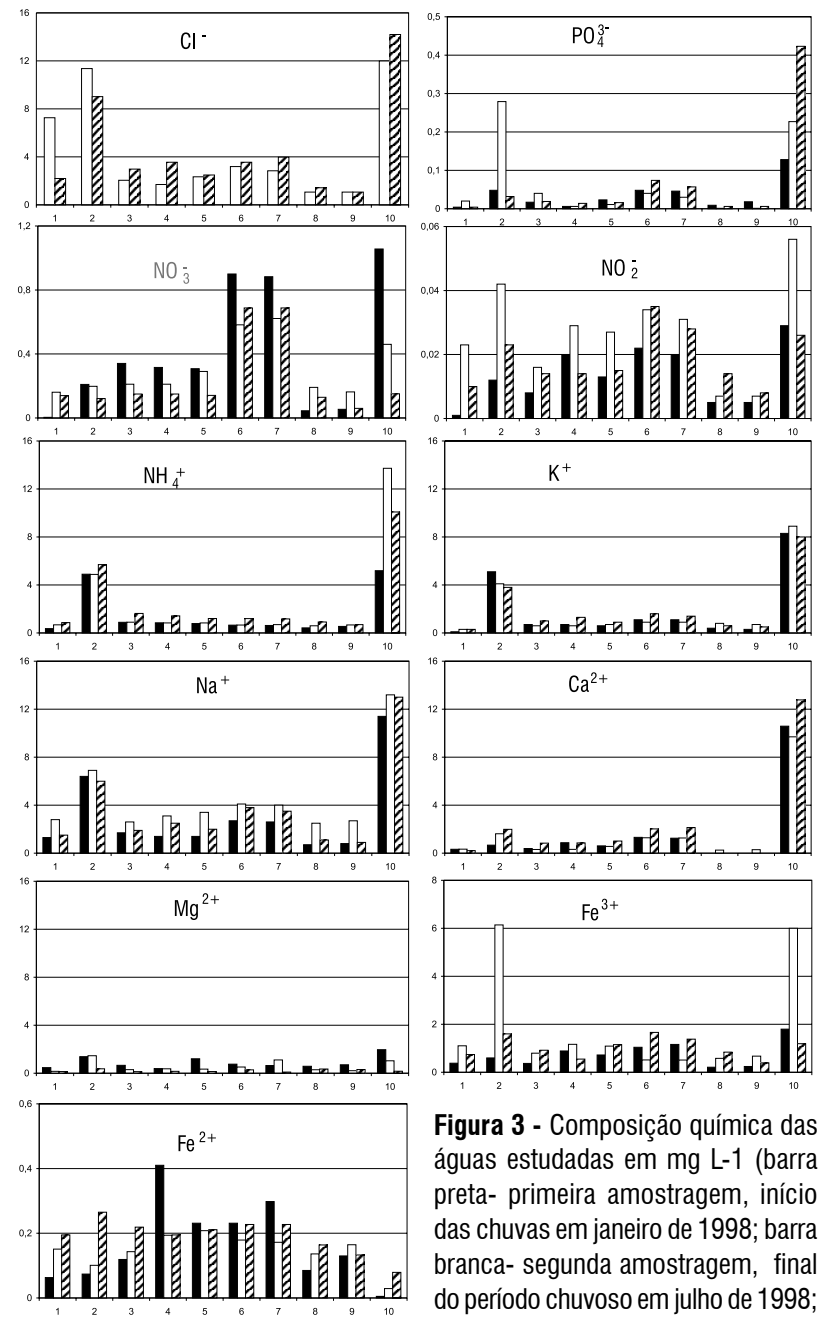

Figura 3 - Composição química das águas estudadas em mg L-1 (barra preta- primeira amostragem, início das chuvas em janeiro de 1998; barra branca- segunda amostragem, final do período chuvoso em julho de 1998; barra axurada- terceira amostragem, período de estiagem em outubro de 1998).

\section{ELEMENTOS CONSIDERADOS ALTAMENTE TÓXICOS}

Dentre esses elementos foram analisados $\mathrm{Ni}, \mathrm{Pb}, \mathrm{Cu}, \mathrm{Zn}$, $\mathrm{Mn}$ e $\mathrm{Cr}$, mas somente nas campanhas de janeiro e julho (início e final do período de maior pluviosidade, respectivamente) (Fig. 4). O Zn é o que apresentou teores mais elevados, enquanto que $\mathrm{Mne} \mathrm{Cr}$ os mais baixos. Nas drenagens os teores variam bastante e não se concentram somente próximo ao aterro (P2) e na água proveniente do bairro de Santa Etelvina (P10) como a maioria dos parâmetros físicos e químicos analisados. $\mathrm{O} \mathrm{Pb}$ é elevado também logo a jusante desses pontos (P3 e P4) e no rio Negro (P9), Cu entre os pontos 4 e 7 do igarapé da Bolívia, Zn no ponto 7 e Mn no rio Negro (P9) (Fig. 4). Entre os períodos Pb, Zn e em parte Ni e Mn têm teores mais elevados no início das chuvas, enquanto o $\mathrm{Cu}, \mathrm{Zn}$ e $\mathrm{Cr}$ se alternam entre essa estação e o final das chuvas (Fig. 4). 
Via de regra, a quantidade de elementos químicos liberados por aterros sanitários é baixa (Looser et al., 1999), pois a maior parte é retida nos resíduos devido a reaçôes de oxidação, redução, troca iônica e coprecipitação, formando sulfetos, carbonatos, fosfatos, além de se combinarem com a matéria orgânica, o que diminui as suas mobilidades (Pepper et al., 1996). Contudo, o $\mathrm{pH}$ ácido das águas de precipitação e subterrânea da região entre 3,5 e 5,5 (Silva et al., 1999 e Silva, 1999) favorece que parte desses elementos passe para a fase dissolvida (Hem, 1970) e alcancem o ambiente superficial. Nesse novo ambiente eles tendem a serem adsorvidos pelo material em suspensão e pelos sedimentos de fundo, como constatado por Barroncas (1999) e Silva et al., (1999) nos igarapés de Manaus e em outros na Amazônia (Mazzeo, 1991).
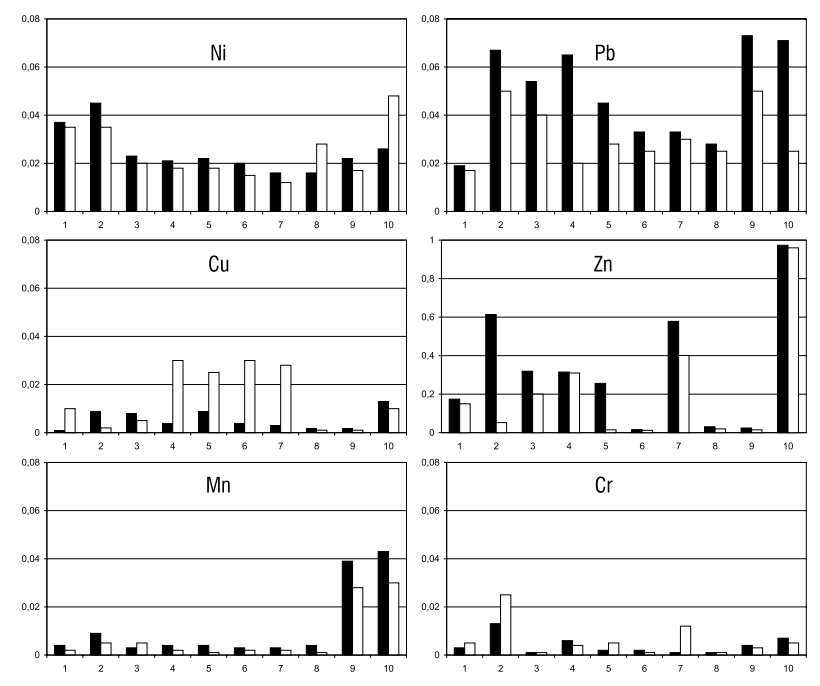

Figura 4 - Teores em mg L-1 dos metais altamente tóxicos (barra pretaprimeira amostragem, início das chuvas em janeiro de 1998; barra brancasegunda amostragem, final do período chuvoso em julho de 1998; barra axurada- terceira amostragem, período de estiagem em outubro de 1998).

\section{DISCUSSÃO}

Somente os compostos nitrogenados, em especial o $\mathrm{NH}_{4}^{+}$, associados a degradação de matéria orgânica do aterro e dos produtos de excreção dos esgotos domésticos, e Ni, $\mathrm{Pb}, \mathrm{Cu}$ e Zn apresentam quantidades consideradas tóxicas ao ambiente (357/ 2005 da CONAMA). Contudo, todos estão, em geral, mais elevados que nas águas naturais o que denota o impacto causado pelo aterro sanitário e pelo esgoto doméstico proveniente de Santa Etelvina. A predominância de $\mathrm{Na}^{+} \mathrm{e} \mathrm{Cl}$ nas águas reflete a pouca reatividade desses íons à formação de compostos precipitáveis e a sua adsorção pelos argilominerais, de modo que as suas concentraçōes diminuem, basicamente, devido à diluição (Christensen et al. 2001). $\mathrm{O} \mathrm{Ca}^{2+}, \mathrm{Mg}^{2+}$ e $\mathrm{K}^{+}$são afetados, além da diluição, por troca iônica, complexação e precipitação, tendem a formar sulfatos, fosfatos e carbonatos. Podem, ainda ser utilizados pela vegetação, o que faz com que suas concentraçōes diminuam mais rapidamente ao longo da drenagem, assim como seus impactos ambientais. Em contrapartida, a presença de fosfato e nitrogênio tende a tornar o ambiente eutrófico (Pepper et al. 1996) o que agrava ainda mais a qualidade das águas. $\mathrm{O} \mathrm{Pb}$ $\left(0,071 \mathrm{mg} \mathrm{L}^{-1}\right)$ e $\mathrm{Mn}\left(0,039 \mathrm{mg} \mathrm{L}^{-1}\right)$, anomalamente elevados no rio Negro (P9), devem refletir a marina localizada à montante desse ponto, contudo teores similares a mais elevados desses elementos foram encontrados no rio Negro a montante de Manaus (Külcher et al. 2000). Provavelmente, a maior disponibilidade de $\mathrm{Zn}$, em relação aos demais elementos tóxicos, pode ser atribuída a tendência deste ser mais estável em ambiente menos ácido (Hem, 1970) como os das águas estudadas.

A variação dos teores ao longo da drenagem (Fig. 2 a 4) permite dividir os elementos em dois grupos: A- com padrão de distribuição semelhante caracterizado pelos teores mais elevados nos pontos afetados diretamente pelo aterro sanitário e pelos esgotos domésticos ( $\mathrm{P} 2$ e 10 respectivamente): $\mathrm{pH}$, condutividade, dureza, alcalinidade, $\mathrm{Cl}^{-}, \mathrm{PO}_{4}^{3-}, \mathrm{NH}_{4}^{+}, \mathrm{K}^{+}, \mathrm{Na}^{+}$, $\mathrm{Ca}^{2+}, \mathrm{Fe}^{3+} \mathrm{e} \mathrm{Ni}$; B- com padrão de distribuição variável: turbidez, $\mathrm{NO}_{3}^{-}, \mathrm{NO}_{2}-\mathrm{Fe}^{2+}, \mathrm{Mg}^{2+}, \mathrm{Pb}, \mathrm{Cu}, \mathrm{Zn}$ e $\mathrm{Cr}$. Esses dois grupos sugerem diferentes mobilidades e/ou fontes para o material dissolvido na área de estudo.

A elevação de $\mathrm{NO}_{3}{ }^{-}$e $\mathrm{NO}_{2}{ }^{-}$no igarapé da Bolívia marca um ambiente mais oxidante, provavelmente associado à cachoeira existente entre os pontos $6 \mathrm{e} 7$, mas isso não se reflete no $\mathrm{Fe}^{2+}$ que é típico de ambientes mais redutores. No ponto $4 \mathrm{o}$ aumento do $\mathrm{Fe}^{2+} \mathrm{e} \mathrm{Pb}$ pode ser conseqüência deste ponto se localizar próximo da confluência do igarapé proveniente do bairro de Santa Etelvina com Matrinchã, contudo, não se descarta a possibilidade de nova fonte de contaminação no igarapé da Bolívia como mostra o aumento da turbidez nesse ponto.

Não foram observadas variaçōes na composição química das águas em função da fonte de contaminação, por parte do aterro ou esgoto. A diferença mais significativa está no teor de $\mathrm{Mn}$ quase quatro vezes mais elevado no material proveniente diretamente dos esgotos. Essa não diferenciação entre as fontes de contaminantes indica que ambas são quimicamente similares e os teores inferiores no ponto 2 podem estar relacionados a fixação parcial dos contaminantes pela matéria orgânica acumulada no aterro sanitário como mencionado anteriormente.

\section{QUALIDADE DAS ÁGUAS}

A integração dos dados por meio da fatorial permitiu definir quais as variáveis que mais influenciam a qualidade das águas e qual o grau de contaminação de cada ponto analisado. Assim, foi considerado o primeiro fator que tem a maior variança (51\%), como o que melhor discriminou o conjunto das variáveis e conseqüentemente o grau de influência destas na qualidade da água (Tab. 1). Do total de variáveis foram selecionadas as que 
apresentaram cargas mais elevadas $(>0,7)$ : condutividade, dureza, alcalinidade, $\mathrm{PO}_{4}^{3-}, \mathrm{NH}_{4}^{+}, \mathrm{K}^{+}, \mathrm{Na}^{+}, \mathrm{Ca}^{2+}, \mathrm{Fe}^{3+} \mathrm{e} \mathrm{Mg}^{+}$(Tab. 1). Essa associação de variáveis sugere íntima relação da contaminação com os produtos de excreção dos esgotos domésticos e, conseqüentemente, com a matéria orgânica, além de surfactantes e reforçadores de detergentes, bem como possivelmente, a restos de material de construção civil, especialmente, cimento.

Considerando-se somente as variáveis mais representativas foram obtidos os escores de cada uma das amostras analisadas. Como os pontos 10 e 2 estão mais próximos da fonte dos despejos dos esgotos domésticos e do aterro sanitário, respectivamente, os seus escores mais altos representam, portanto, as zonas mais contaminadas. Assim, as zonas entre os pontos 6 e 7 no igarapé da Bolívia e entre os pontos 3 e 5 na confluência do Matrinchã com o proveniente de Santa Etelvina, em ordem decrescente de escores (Tab. 2 e Fig. 5), apresentam grau de contaminação menor. Esses dados demonstram que há uma terceira fonte de contaminação no igarapé da Bolívia entre os pontos 6 e 7 associada ao maior número de moradores na área. A cabeceira do igarapé Matrinchã (P1) e os rios Tarumã-Açú e Negro (P8 e P9, respectivamente) com os escores mais baixos são os que apresentam a melhor qualidade de água na área estudada (Tab. 2 e Fig. 5).

Comparando os escores nos três períodos analisados, observase que de modo geral há tendência da qualidade da água melhorar no início das chuvas no igarapé da Bolívia (P6 a P8), enquanto, para montante não há diferenças marcantes entre o início e a estiagem na cabeceira do Matrinchã (P1) e entre início e final das chuvas na confluência entre este e o proveniente de Santa Etelvina (P3 e P4) (Tab. 2). No início do igarapé da Bolívia (P5) a qualidade melhora para o final das chuvas e na estiagem. No rio Negro (P9) há uma leve tendência de melhora na qualidade das

Tabela 1 - Fatores das variáveis analisadas considerando os três períodos estudados.

\begin{tabular}{lll}
\hline Variáveis & Fator $\mathbf{1}$ & Fator 2 \\
\hline $\mathrm{pH}$ & 0,68 & 0,33 \\
Condutividade & 0,97 & 0,10 \\
Turbidez & 0,14 & $-0,75$ \\
Dureza & 0,95 & 0,17 \\
Alcalinidade & 0,96 & 0,13 \\
$\mathrm{P03}-4$ & 0,84 & $-0,33$ \\
$\mathrm{NO}-3$ & 0,43 & 0,01 \\
$\mathrm{NO}-2$ & 0,69 & $-0,66$ \\
$\mathrm{NH}+4$ & 0,91 & $-0,09$ \\
$\mathrm{~K}+$ & 0,98 & 0,10 \\
$\mathrm{Na} 2+$ & 0,97 & $-0,08$ \\
$\mathrm{Ca} 2+$ & 0,91 & 0,12 \\
$\mathrm{Fe} 3+$ & 0,75 & $-0,48$ \\
$\mathrm{Fe} 2+$ & $-0,52$ & $-0,30$ \\
$\mathrm{Mg} 2+$ & 0,77 & 0,18 \\
\hline
\end{tabular}

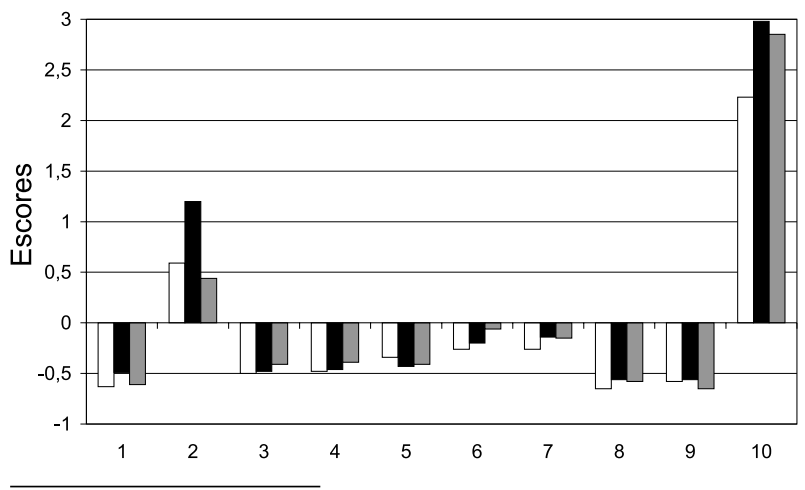

Figura 5 - Escores das amostras coletadas no início das chuvas (barras brancas), no final das chuvas (barra preta) e na estiagem (barra cinza).

Tabela 2 - Escores das amostras obtidos por análise de componentes principais.

\begin{tabular}{llll}
\hline Pontos & Início das chuvas & Final das chuvas & Estiagem \\
\hline 1 & $-0,63$ & $-0,49$ & $-0,61$ \\
2 & 0,59 & 1,20 & 0,44 \\
3 & $-0,50$ & $-0,48$ & $-0,41$ \\
4 & $-0,48$ & $-0,46$ & $-0,39$ \\
5 & $-0,34$ & $-0,43$ & $-0,41$ \\
6 & $-0,26$ & $-0,20$ & $-0,06$ \\
7 & $-0,26$ & $-0,14$ & $-0,15$ \\
8 & $-0,65$ & $-0,56$ & $-0,58$ \\
9 & $-0,58$ & $-0,56$ & $-0,65$ \\
10 & 2,23 & 2,98 & 2,85 \\
\hline
\end{tabular}

águas na estiagem (escores de -0,58 para -0,65). A pior qualidade da área estudada foi no igarapé proveniente de Santa Etelvina (P10) no final das chuvas $(2,98)$ e na estiagem $(2,85)$ e no ponto 2 mais próximo do aterro no final das chuvas $(1,2)$. Essas variaçōes mostram que a época de amostragem deve ser levada em consideração, mas que a influência não é constante em todos os pontos.

\section{CONCLUSÃO}

O aterro sanitário e os esgotos domésticos afetam, consideravelmente a composição das águas da bacia do Tarumã, modificando todas as suas características quando comparadas com águas naturais da região. Houve aumento de $\mathrm{pH}$, condutividade, dureza e alcalinidade, $\mathrm{Cl}, \mathrm{PO}_{4}^{3-}, \mathrm{NH}_{4}^{+}, \mathrm{K}^{+}, \mathrm{Na}^{2+}$, $\mathrm{Ca}^{2+}, \mathrm{Fe}^{3+}, \mathrm{Ni}, \mathrm{Pb}, \mathrm{Zn}$ e Mn nas águas próximas do aterro (P2) e do bairro de Santa Etelvina (P10). Contudo, somente $\mathrm{NH}_{4}^{+}$, $\mathrm{Ni}, \mathrm{Pb}, \mathrm{Cu}$ e $\mathrm{Zn}$ apresentaram concentraçōes elevadas para os padrôes de águas de uso doméstico. A maioria dos teores dos íons dissolvidos é compatível com os encontrados em outros igarapés contaminados em Manaus, contudo, deve-se destacar que o $\mathrm{Cl}^{-}$ , $\mathrm{K}^{+}, \mathrm{Na}^{2+} \mathrm{e} \mathrm{Ca}^{2+}$ apresentaram-se bem mais concentrados, especialmente no igarapé proveniente do bairro de Santa Etelvina 
(P10). Foi constatada que além do aterro e dos esgotos do bairro de Santa Etelvina, os moradores ao longo do igarapé da Bolívia, pontos 6 e 7, representam nova fonte de contaminação na bacia do Tarumã. A incompatibilidade entre os teores do par redutor $\mathrm{NH}_{4}^{+}-\mathrm{Fe}^{2+}$ e o oxidante $\mathrm{NO}_{3}{ }_{-}^{-}-\mathrm{Fe}^{3+}$ deverá ser mais bem estudada em trabalhos futuros.

Não foi possível diferenciar variaçôes em função da fonte, se do aterro ou dos esgotos. Isso indica que ambas são quimicamente similares e que os teores inferiores no ponto 2 podem estar relacionados a fixação parcial dos contaminantes pela matéria orgânica acumulada no aterro sanitário.

A análise fatorial indica que a condutividade, dureza, alcalinidade, $\mathrm{PO}_{4}^{3-}, \mathrm{NH}_{4}^{+}, \mathrm{K}^{+}, \mathrm{Na}^{+}, \mathrm{Ca}^{2+}, \mathrm{Fe}^{3+} \mathrm{e} \mathrm{Mg}^{+}$são os índices que melhor qualificaram as águas estudadas e que há tendência da qualidade ser um pouco melhor no início das chuvas entre o igarapé da Bolívia e o Tarumã-Açú (P6 a P8), enquanto não há diferenças marcantes entre o início e a estiagem na cabeceira do Matrinchã (P1) e entre início e o final das chuvas na confluência do Matrinchã com o igarapé proveniente de Santa Etelvina. Essas variações comprovam a influência do período pluviométrico, mas que esta não é constante para toda a drenagem e, apesar da tendência das águas serem mais diluídas no final do período chuvoso isto não significa que a qualidade melhora significativamente.

\section{AGRADECIMENTOS}

Os autores agradecem a Universidade Federal do Amazonas e ao Instituto Nacional de Pesquisa da Amazônia pela infraestrutura dos laboratórios e ao CNPq pela bolsa de iniciação científica ao primeiro autor. Agradecem também as sugestôes dos revisores que ajudaram a melhorar a qualidade do trabalho.

\section{BIBLIOGRAFIA}

Barroncas, P.S.R. 1999. Estudo da concentração de metais pesados nos igarapés Matrinchã, Acará, Bolivia e Tarumã (Manaus -AM). Manaus. Master's Thesis, Centro de Ciências do Ambiente, Universidade Federal do Amazonas, Manaus, Amazonas. 95pp.

Campos, Z.E.S. de. 1994. Parâmetros físico-quimicos em igarapé de água clara e preta ao longo da rodovia BR-174 entre Manaus e Presidente Figueiredo - AM. Master's Thesis, em Biologia Tropical e Recursos Naturais, Instituto Nacional de Pesquisas da Amazônia, Manaus, Amazonas. 54 pp.

Christensen, T.H.; Kjeldsen, P; Bjerg, P.L.; Jensen, D.L.Christensen, J.B.; Baun, A.; Albrechtsen H-J. Heron, G. 2001. Biogeochemistry of landfill leachate plumes. Applied Geochemistry, 16: 658-718.
Cunha, P.R.C.; Gonzaga, F.G.; Coutinho,L.F.C.; Feijó, F.J. 1994. Bacia do Amazonas. Boletim de Geociências da PETROBRAS, 8: 47-55.

Grossi, M.G.L. 1993. Avaliação da qualidade dos produtos obtidos de usinas de compostagem brasileira de lixo doméstico através da determinação de metais pesados e substâncias orgânicas tóxicas. Doctor Thesis, Instituto de Química, Universidade de São Paulo, São Paulo. 135 pp.

Hasse, J.; Krieger, J.A.; Possoli, S. 1989. Estudo da viabilidade do uso da técnica de análise fatorial como um instrumento na interpretação da qualidade da água da bacia hidrográfica do Guaíba, RS, Brasil. Ciência e Cultura, 41: 576-582.

Hem, J.D. 1970. Study and interpretation of the chemical characteristics of natural waters. U.S. Government Printing Office, Washington. 363pp.

Külcher, I.L.; Miekeley, N.; Forsberg, B.R. 2000. A contribution to the chemical characterization of rivers in the rio Negro Basin, Brazil. Journal of Brazilian Chemestry, 11: 286-292.

Leal, P.C. 1996. Caracterização e interpretações genéticas de alguns solos da região de Manaus - AM. Dissertação de Mestrado. UFPe. 109pp.

Looser, M.O.; Parriaux, A.; Bensimon, M. 1999. Landfill underground pollution detection and characterization using inorganic traces. Water Research, 33, p. 3609-3616.

Mazzeo, T.E. 1991. Avaliação ambiental das vias de drenagem na região metropolitana de Belém (PA) quanto a distribuição dos elementos $\mathrm{Ca}, \mathrm{Cd}, \mathrm{Cr}, \mathrm{Cu}, \mathrm{Fe}, \mathrm{Hg}, \mathrm{K}, \mathrm{Mg}, \mathrm{Mn}, \mathrm{Na}, \mathrm{Ni}, \mathrm{Pb}, \mathrm{e} \mathrm{Zn}$. Master's Thesis, Centro de Geociências, Universidade Federal do Pará, Belém. 138pp.

Pepper, I.L.; Gerba, C.P.; Brusseau, M.L. 1996. Pollution Science. Academic Press. London, UK. 397pp.

Santos U. M., Bringel S. R. B., Bergamin F. H., Ribeiro M. N. G.; Bananeira M. 1984. Rios da Bacia Amazônica I - Afluentes do rio Negro. Acta Amazonica, 14 (1-2): 222-237.

Santos, U. M.; Ribeiro, M. N. G. 1988. A hidroquímica do rio Solimóes-AM. Acta Amazonica, 18 (3-4): 145-172.

Silva, M.S.R.; Ramos, J.P.; Pinto, A.G..N. 1999. Metais de transição nos sedimentos de igarapés de Manaus-AM. Acta Limnologica Brasiliensis, 11: 89-100.

Silva, M. L. 1999. Hidroquímica elementar e dos isótopos de urânio nos aqüiferos de Manaus-AM. Master's Thesis, Universidade de São Paulo, Rio Claro, São Paulo. 135pp.

Sioli, H. 1957. Valores de $\mathrm{pH}$ de águas Amazônicas. Boletim do Museu Paraense Emilio Goeldi. Geologia, 1: 1-35.

Recebido em 22/12/2004

Aceito em 04/04/2006 